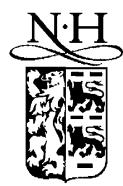

ELSEVIER
Available online at www.sciencedirect.com

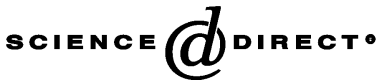

Nuclear Instruments and Methods in Physics Research A 501 (2003) 623-629

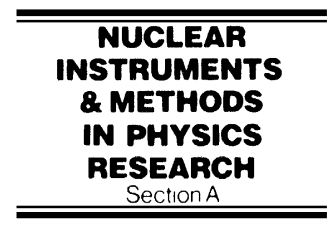

www.elsevier.com/locate/nima

\title{
A metastable xenon isotope detector for treaty verification
}

\author{
J.A.M. Lopes ${ }^{\mathrm{a}, \mathrm{b}, *}$, R.E. Morgado ${ }^{\mathrm{c}}$, C.A.N. Conde ${ }^{\mathrm{b}}$ \\ ${ }^{a}$ Instituto Superior de Engenharia de Coimbra, Ap. 4065, 3030 Coimbra, Portugal \\ ${ }^{\mathrm{b}}$ Faculdade de Ciencias e Tecnologia, Departamento de Física, Universidade de Coimbra, 3004-516 Coimbra, Portugal \\ ${ }^{\mathrm{c}}$ Los Alamos National Laboratory, Los Alamos, NM, USA
}

Received 11 October 2002; received in revised form 6 January 2003; accepted 20 January 2003

\begin{abstract}
A system to selectively detect and quantify the xenon metastable isotopes ${ }^{131 \mathrm{~m}} \mathrm{Xe},{ }^{133 \mathrm{~m}} \mathrm{Xe},{ }^{133} \mathrm{Xe}$, and ${ }^{135} \mathrm{Xe}$ has been designed, fabricated, and tested. The system combines high-resolution electron and gamma-ray spectrometry with coincidence/anti-coincidence timing for signal selectivity and background rejection. By utilizing X-ray-fluorescence gating, backgrounds from other sources are expected to be reduced to the sub-becquerel level. Coincidence and anticoincidence triggers are formed from the several individual detectors that comprise the system and used to identify $\mathrm{K}$-shell conversion electrons and fluorescence X-rays from a ${ }^{109} \mathrm{Cd}$ test source with good efficiencies and energy resolutions ( $20 \mathrm{keV}$ for the low-energy electrons, $\sim 1.2 \mathrm{keV}$ for the fluorescence $\mathrm{X}$-rays, respectively).
\end{abstract}

(C) 2003 Elsevier Science B.V. All rights reserved.

Keywords: Radioxenon; Xenon; Multiparameter detection system; Treaty verification; CTBT

\section{Introduction}

Secret underground nuclear tests intended to circumvent nuclear test-ban treaties will very likely vent gases into the atmosphere that contain xenon fission products. However, the collectible levels of radioxenon isotopes may be very low, perhaps as low as $1 \mathrm{mBq} / \mathrm{m}^{3}$ of air, and extremely sensitive detection techniques $(20-100 \mu \mathrm{Bq})$ will be necessary to detect treaty violators [1]. The xenon isotopes of interest are ${ }^{131 \mathrm{~m}} \mathrm{Xe}$ (11.9 day), ${ }^{133 \mathrm{~m}} \mathrm{Xe}$ (2.2 day), ${ }^{133} \mathrm{Xe}$ (5.3 day) and ${ }^{135} \mathrm{Xe}(9.1 \mathrm{~h})$ as a

\footnotetext{
*Corresponding author. Faculdade de Ciencias e Tecnologia, Departamento de Física, Universidade de Coimbra, 3004-516 Coimbra, Portugal. Tel.: +351-239-410667; fax: +351-239829158.

E-mail address: fcjam@gian.fis.uc.pt (J.A.M. Lopes).
}

result of their relative abundances and longer halflives following a detonation. The fission yield of a $1-\mathrm{kT}$ plutonium bomb produces $5 \times 10^{9} \mathrm{~Bq}$ of ${ }^{131 \mathrm{~m}} \mathrm{Xe}, 2 \times 10^{13} \mathrm{~Bq}$ of ${ }^{133 \mathrm{~m}} \mathrm{Xe}, 2 \times 10^{14} \mathrm{~Bq}$ of ${ }^{133} \mathrm{Xe}$ and $2 \times 10^{16} \mathrm{~Bq}$ of ${ }^{135} \mathrm{Xe}$ [1]. Fig. 1 shows simplified level schemes for the four isotopes.

The principal decay products of each isotope provide the distinctive signatures listed in Table 1. Each signature includes simultaneous emissions that can potentially reduce background with the use of coincidence techniques. The isomeric transitions of ${ }^{131 \mathrm{~m}} \mathrm{Xe}$ and ${ }^{133 \mathrm{~m}} \mathrm{Xe}$ to ${ }^{131} \mathrm{Xe}$ and ${ }^{133} \mathrm{Xe}$ occur with the emission of either a gamma ray or a conversion electron (CE) in coincidence with a xenon fluorescence X-ray. The two other isotopes of interest, ${ }^{133} \mathrm{Xe}$ and ${ }^{135} \mathrm{Xe}$, decay by beta emission to their respective daughter cesium isotopes, followed also by either a gamma ray or 


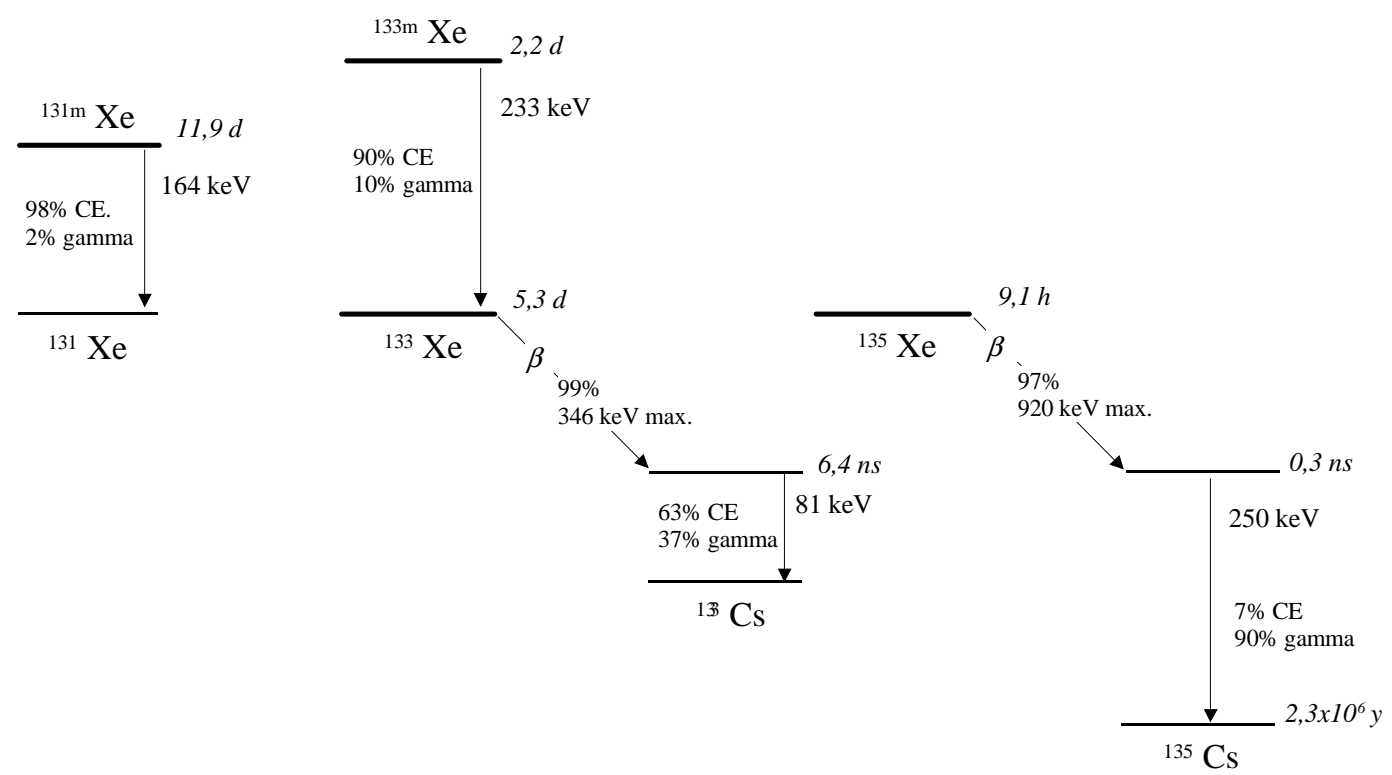

Fig. 1. Simplified level schemes of ${ }^{131 \mathrm{~m}} \mathrm{Xe},{ }^{133 \mathrm{~m}} \mathrm{Xe},{ }^{133} \mathrm{Xe}$ and ${ }^{135} \mathrm{Xe}$, indicating transition energies and branching ratios for the states of interest $(\mathrm{CE}=$ conversion electron) $[2]$.

a $\mathrm{CE}$ in coincidence with a cesium fluorescence $\mathrm{X}$-ray.

The branching ratios favor the CEs instead of the gamma rays, except for the case of ${ }^{135} \mathrm{Xe}$ where the CEs correspond to $7 \%$ of the decays. The fact that ${ }^{135} \mathrm{Xe}$ is produced in much larger amounts when compared with the other three isotopes makes it reasonable to consider its detection only by CEs.

Taking into account that each $\mathrm{CE}$ is emitted together with a fluorescence X-ray, a system capable of detecting and identifying both radiations in coincidence would significantly reduce background.

\section{Theory of operation}

We assume that the concentrated gas sample containing the xenon isotopes is extracted from a large volume of sampled air by well-developed methods. The sample is directed into a beryllium sample chamber in the center of the detector (Fig. 2). The detector consists of the beryllium central sample chamber and CE spectrometer, surrounded by two gas proportional scintillator counters (GPSCs), as shown in Fig. 2. A multiwire proportional counter (MWPC) is located within the beryllium pillbox while two silicon charged-particle detectors line the top and bottom of the beryllium pillbox. The beryllium pillbox functions as both the sample chamber and the range-absorber for the beta-decay products that constitute a major source of background in the GPSCs.

CEs from the sample will, in most cases, deposit a fraction of their energy in the xenon gas, while the remaining energy is deposited in one of the two silicon detectors. The total energy of the electron will then be the sum of the energies deposited in the three sample chamber detectors. X-rays that are emitted in coincidence with every CE escape the sample chamber and are detected in the surrounding GPSCs, completing the signature for valid events in the sample chamber.

The state-of-the-art GPSCs are simple, robust and highly efficient devices with the best energy resolution among the room temperature X-ray detectors (1.4 at $30 \mathrm{keV}$ ) [3]. K-fluorescence X-rays from cesium and xenon can be resolved, allowing 
the distinction between the overlapping $\mathrm{CE}$ energies from ${ }^{133 m} \mathrm{Xe}$ and ${ }^{135} \mathrm{Xe}$.

Cosmic-ray background will most likely deposit energy in both GPSCs. The detection of

Table 1

Main decay products of ${ }^{131 \mathrm{~m}} \mathrm{Xe},{ }^{133 \mathrm{~m}} \mathrm{Xe},{ }^{133} \mathrm{Xe},{ }^{135} \mathrm{Xe}[2]$

\begin{tabular}{|c|c|c|}
\hline Energy (keV) & Intensity $(\%)$ & Emissions \\
\hline \multicolumn{3}{|l|}{${ }^{131 \mathrm{~m}} \mathrm{Xe}$} \\
\hline 164 & 2 & $\gamma$ \\
\hline 163 & 7 & $\mathrm{CE}+\mathrm{X}(\mathrm{Xe}-\mathrm{M}<1 \mathrm{keV})$ \\
\hline 159 & 29 & $\mathrm{CE}+\mathrm{X}(\mathrm{Xe}-\mathrm{L} \approx 4.3 \mathrm{keV})$ \\
\hline 129 & 61 & $\mathrm{CE}+\mathrm{X}(\mathrm{Xe}-\mathrm{K} \approx 30 \mathrm{keV})$ \\
\hline \multicolumn{3}{|l|}{${ }^{133 \mathrm{~m}} \mathrm{Xe}$} \\
\hline 233 & 10 & $\gamma$ \\
\hline 233 & 1 & $\mathrm{CE}+\mathrm{X}(\mathrm{Xe}-\mathrm{N}, \mathrm{Xe}-\mathrm{O}<<1 \mathrm{keV}$ \\
\hline 232 & 5 & $\mathrm{CE}+\mathrm{X}(\mathrm{Xe}-\mathrm{M}<1 \mathrm{keV})$ \\
\hline 228 & 21 & $\mathrm{CE}+\mathrm{X}(\mathrm{Xe}-\mathrm{L} \approx 4.3 \mathrm{keV})$ \\
\hline 199 & 63 & $\mathrm{CE}+\mathrm{X}(\mathrm{Xe}-\mathrm{K} \approx 30 \mathrm{keV})$ \\
\hline \multicolumn{3}{|l|}{${ }^{133} \mathrm{Xe}$} \\
\hline 346 (max.) & 99 & $\beta^{-}$ \\
\hline 81 & 37 & $\gamma$ \\
\hline 80 & 2 & $\mathrm{CE}+\mathrm{X}(\mathrm{Cs}-\mathrm{M}<1 \mathrm{keV})$ \\
\hline 75 & 8 & $\mathrm{CE}+\mathrm{X}(\mathrm{Cs}-\mathrm{L} \approx 4.5 \mathrm{keV})$ \\
\hline 45 & 53 & $\mathrm{CE}+\mathrm{X}(\mathrm{Cs}-\mathrm{K} \approx 31 \mathrm{keV})$ \\
\hline \multicolumn{3}{|l|}{${ }^{135} \mathrm{Xe}$} \\
\hline 920 (max.) & 97 & $\beta^{-}$ \\
\hline 608 & 3 & $\gamma$ \\
\hline 250 & 90 & $\gamma$ \\
\hline 244 & 1 & $\mathrm{CE}+\mathrm{X}(\mathrm{Cs}-\mathrm{L} \approx 4.5 \mathrm{keV})$ \\
\hline 214 & 6 & $\mathrm{CE}+\mathrm{X}(\mathrm{Cs}-\mathrm{K} \approx 31 \mathrm{keV})$ \\
\hline
\end{tabular}

Note: Presented X-ray energies are average values. each X-ray in a single GPSC and in a reduced energy window will allow for further reduction in background, with the GPSCs working in anticoincidence.

\section{Detection system}

In the sample chamber, two silicon surfacebarrier detectors are placed face-to-face, spaced $0.8-\mathrm{cm}$ apart. Gold-plated tungsten wires $25 \mu \mathrm{m}$ in diameter and $0.4-\mathrm{cm}$ apart create an MWPC defined by the two silicon detectors with the gas sample as the filling gas. The silicon detectors and MWPC are enclosed in a 5 -mm-thick beryllium pillbox that forms the envelope of the gas sample chamber. About $97 \%$ of the $30-31 \mathrm{keV}$ K-shell $\mathrm{X}$-rays are transmitted through the beryllium while $60 \%$ of the L-shell fluorescence X-rays $(4.3-4.5 \mathrm{keV})$ are transmitted.

The fully depleted silicon detectors have $4.5 \mathrm{~cm}^{2}$ $(2.4 \mathrm{~cm}$ in diameter) active areas and $400-\mu \mathrm{m}$ sensitive depths with electron-energy resolution of $15 \mathrm{keV}$. The face-to-face geometry will allow a high detection probability of the backscattered electrons from one of the silicon surfaces, estimated to be up to $35 \%$ [4]. The thin ceramic spacer ring used between the silicon detectors also serves as the support structure for the MWPC wires.

The sample chamber is surrounded by twin GPSCs, with 14.2-cm diameter and 6.0-cm height enclosed in the same stainless-steel container with

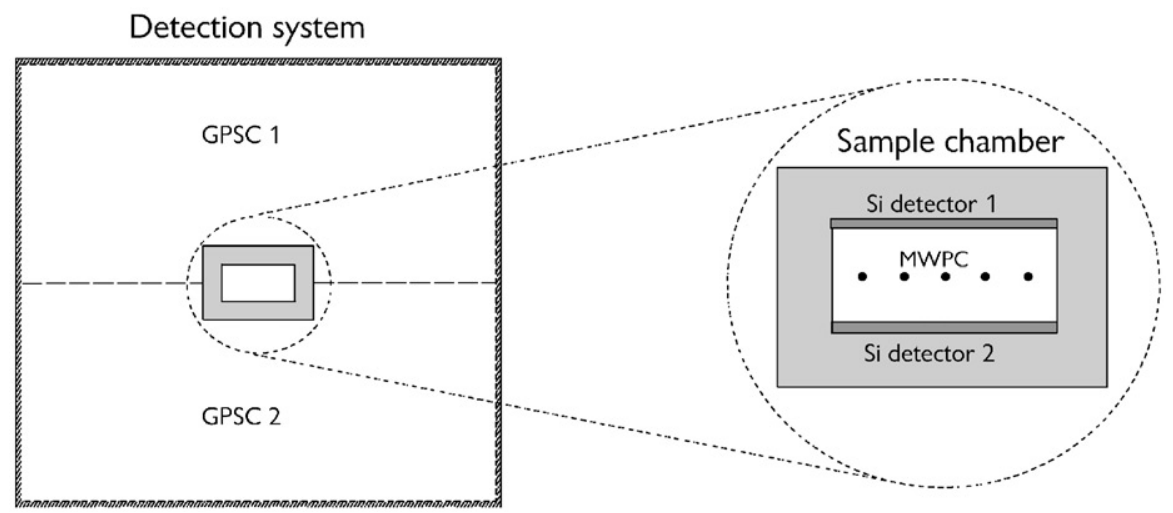

Fig. 2. Detection system schematic showing in detail the sample chamber that is also the CE spectrometer. 


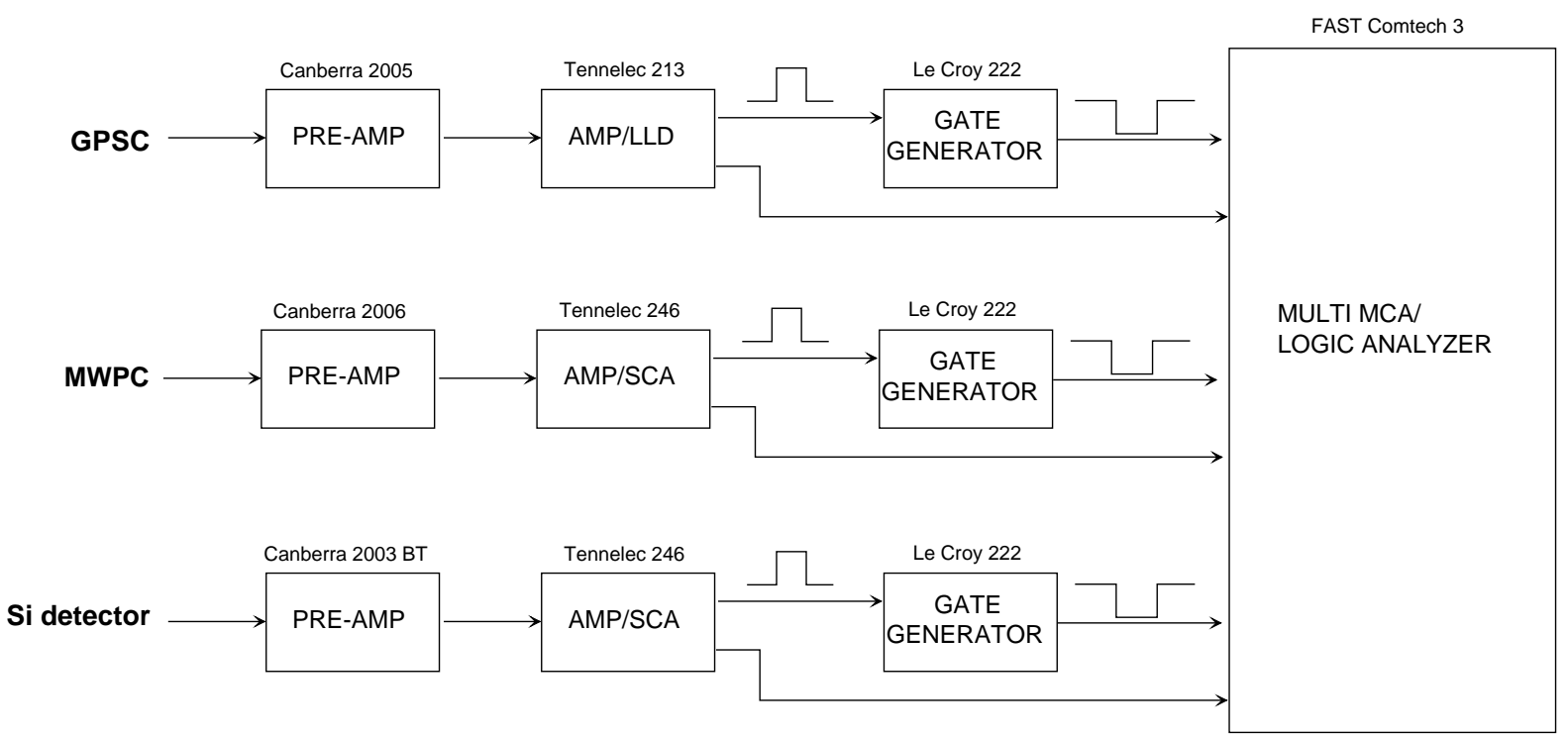

Fig. 3. Electronic configuration for signal formatting and analysis originated in each of the three types of detectors used: GPSC, MWPC and Si detector.

a light barrier between them to prevent cross talk. The total volume of the detection system is $1.9 \mathrm{dm}^{3}$. The energy resolution of the GPSC was measured to be $1.4 \mathrm{keV}$ for $30 \mathrm{keV} \mathrm{X}$-rays.

A block diagram of the electronic circuit is depicted in Fig. 3, showing the signal routing for each of the three different types of detectors used. When a signal falls within the energy window set for a particular detector, a logic signal is generated for coincidence analysis in the FAST ComTech multi-MCA and logic analyzer unit.

\section{Detector operation}

The K-shell fluorescence X-rays have the highest yields ranging from $62 \%$ for ${ }^{131 \mathrm{~m}} \mathrm{Xe}$ to $86 \%$ in the case of ${ }^{135} \mathrm{Xe}$. They also have the highest probabilities of escaping the sample chamber compared with the lower energy fluorescences.

The efficiency of the system for detection of CEs in coincidence with the accompanying $\mathrm{K}$-shell Xray was calculated by Monte Carlo simulation. CE detection efficiency in the $3.6-\mathrm{cm}^{3}$ sample chamber was calculated for a $10-\mathrm{cm}^{3}$ xenon gas sample and was determined to be about $60 \%$.
For the present conditions, $10 \%$ of the $30-\mathrm{keV}$ $\mathrm{X}$-rays are absorbed in the xenon gas sample, 10\% in the silicon detectors, and only $1.3 \%$ in the beryllium absorber. Of the $79 \%$ that escape the sample chamber, $74 \%$ of the $30-\mathrm{keV} \mathrm{X}$-rays are absorbed in the GPSCs, for a xenon filling pressure of $10 \mathrm{~atm}$. Since the K-shell fluorescence yield for xenon is $89 \%$ and for $89.5 \%$ for cesium, the system detection efficiency is $89 \% \times$ $74 \% \times 60 \%=40 \%$.

The system was tested with a $100 \mathrm{nCi}{ }^{109} \mathrm{Cd} \mathrm{CE}$ source to mimic the xenon isotopes. This source emits CEs with 63 and $85 \mathrm{keV}$, in the lower energy range in the region of interest. The $63-\mathrm{keV}$ CEs are detected in coincidence with 22.1 - and $25.0-\mathrm{keV}$ $\mathrm{K}$-shell fluorescence X-rays from silver. For testing with this source, one of the silicon detectors was replaced by a dummy and the cadmium source was epoxied to its surface in a central position. Only one of the two GPSCs was available, reducing the system detection efficiency by about one-half.

Measurements performed with the sample chamber under vacuum showed that the silicon detector has an energy resolution of $20 \mathrm{keV}$ for the $63-\mathrm{keV}$ CEs and $15 \mathrm{keV}$ at $85 \mathrm{keV}$. Measurements of the silicon detectors in a black box showed that 


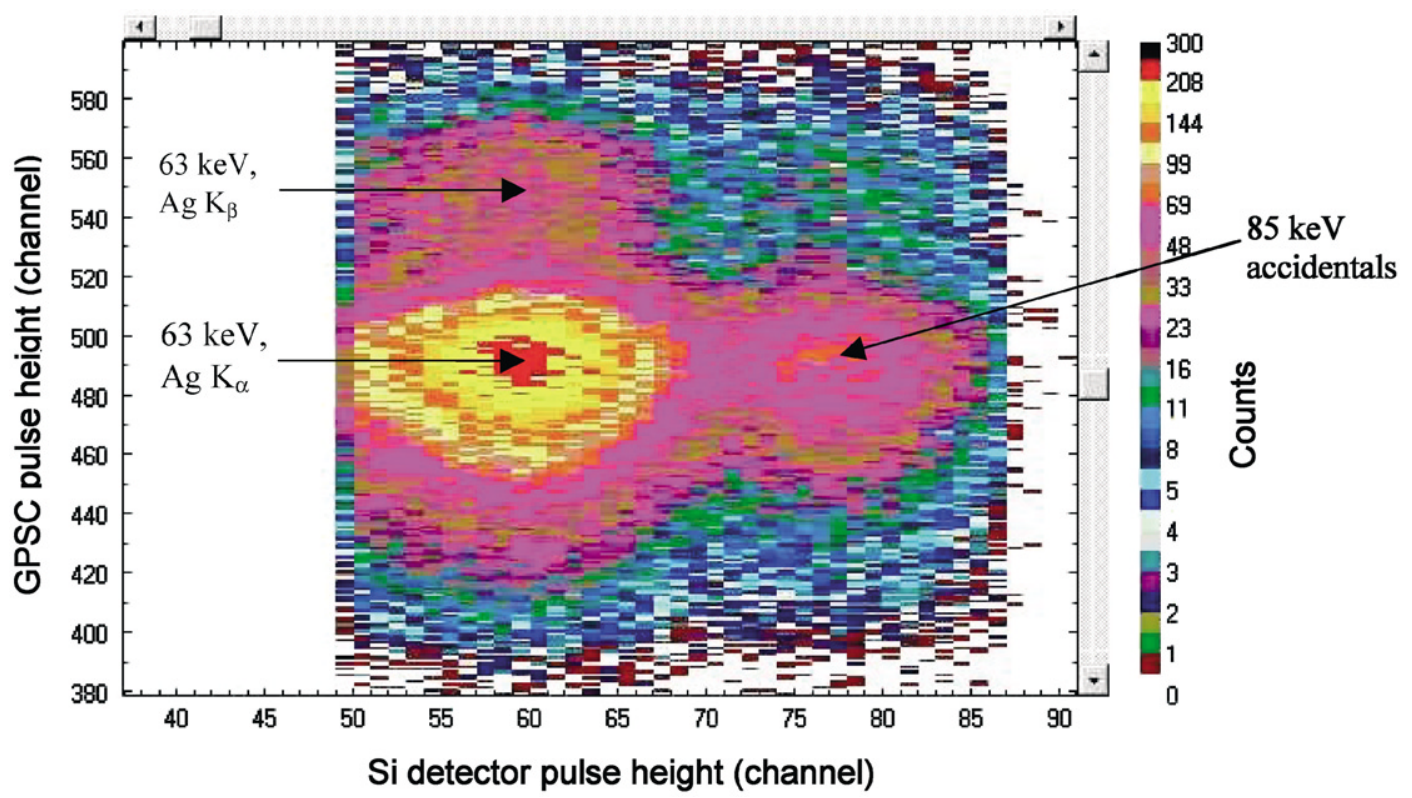

Fig. 4. Two-dimensional histogram of ${ }^{109} \mathrm{Cd}$ coincident detection of $\mathrm{K}$-shell $\mathrm{CE}$ and X-ray.

the energy resolution does not exceed $15 \mathrm{keV}$ for CEs with higher energies, in the region of interest. Below $63 \mathrm{keV}$ the energy resolution degrades to $25 \mathrm{keV}$ for $45-\mathrm{keV}$ CEs. This is due to the proximity of the low-energy noise-level tail that extends up to about $25 \mathrm{keV}$.

\subsection{Silicon detector/GPSC coincidence detection}

With the sample chamber under vacuum, CEs detected by the silicon detector were measured in coincidence with the $\mathrm{K}$-shell silver fluorescence measured in the GPSC. Energies above $19 \mathrm{keV}$ in the GPSC will validate the signals in the silicon detector in the $30-120 \mathrm{keV}$ energy window, including most of the 63- and 85-keV CE peaks. Fig. 4 shows the measured two-dimensional pulse-height histogram. Although the coincidence is set only for the K-shell CEs, the source activity is high enough to have $85 \mathrm{keV}$ accidentals in the $60-\mu$ s coincidence time window. In the case of the xenon isotope detection the count rate will be at least five orders of magnitude smaller and thus accidental detection has no significant effect.
The dual-parameter data capability is demonstrated by the enhanced separation of CEs with overlapping energies and different $\mathrm{X}$-ray energies. In the present case the $63-\mathrm{keV}$ CEs are emitted together with either a silver $K_{\alpha}(22.1 \mathrm{keV})$ or $K_{\beta}(25.0 \mathrm{keV})$ fluorescence.

\subsection{Sample chamber/GPSC coincidence detection}

The sample chamber was filled with xenon in order to evaluate its performance as a $\mathrm{CE}$ spectrometer. A coincidence between the MWPC and silicon detector is gated by detected energies above $19 \mathrm{keV}$ in the GPSC.

The measurement result selecting only the 63$\mathrm{keV}$ peak in the silicon detector is shown in Fig. 5. The sample chamber was filled with $2 \mathrm{~atm}$ of xenon and the MWPC was operated at $900 \mathrm{~V}$. The 63$\mathrm{keV}$ electrons deposit an average of $15 \mathrm{keV}$ in the $8-\mathrm{mm}$-thick MWPC. The straight lobe of the coincidences is detached from low-energy noiselevel of both the silicon detector and the MWPC, operated at a very low gain - about 10-(noise $\sim 4 \mathrm{keV})$. 


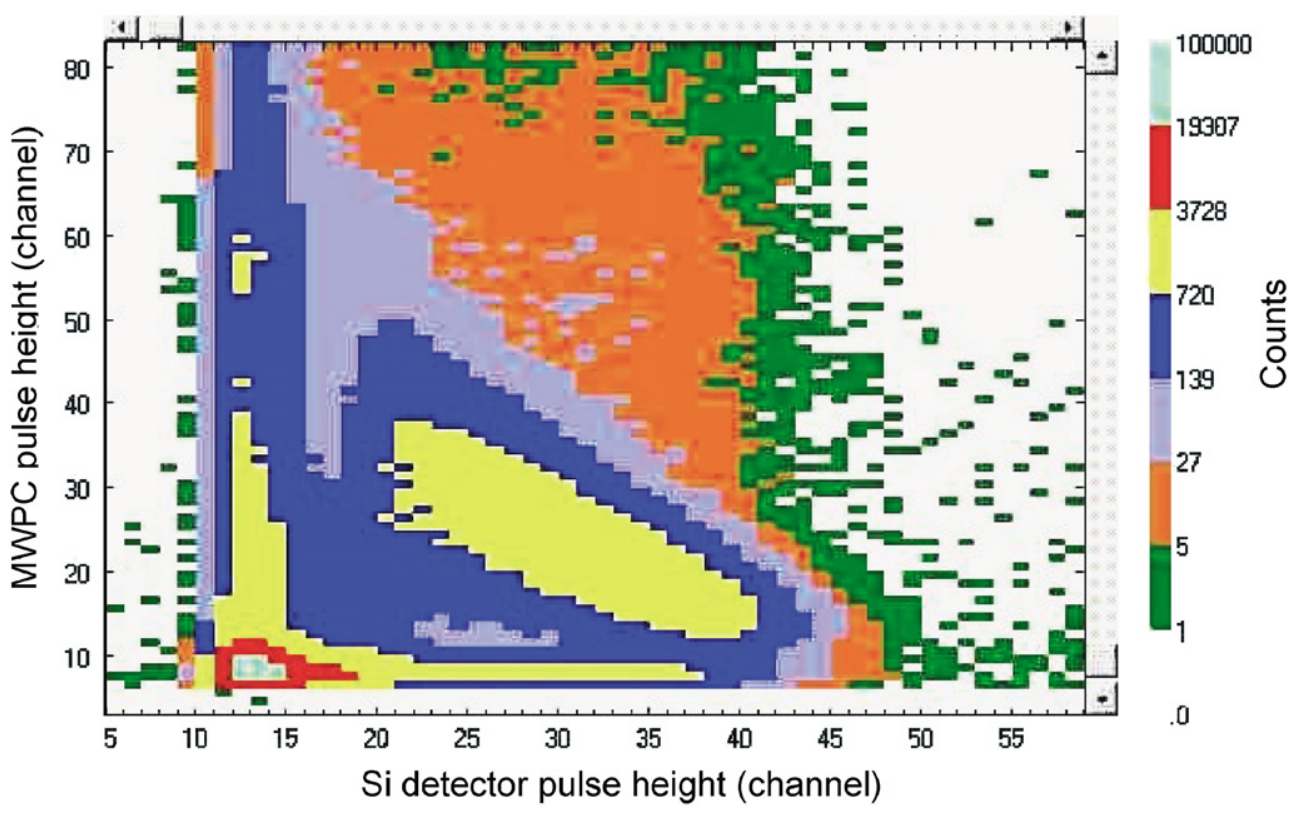

Fig. 5. Two-dimensional histogram of $63 \mathrm{keV} \mathrm{CE} \mathrm{coincident} \mathrm{detection} \mathrm{for} 2 \mathrm{~atm}$ xenon pressure in the sample chamber and $900 \mathrm{~V}$ in the MWPC.

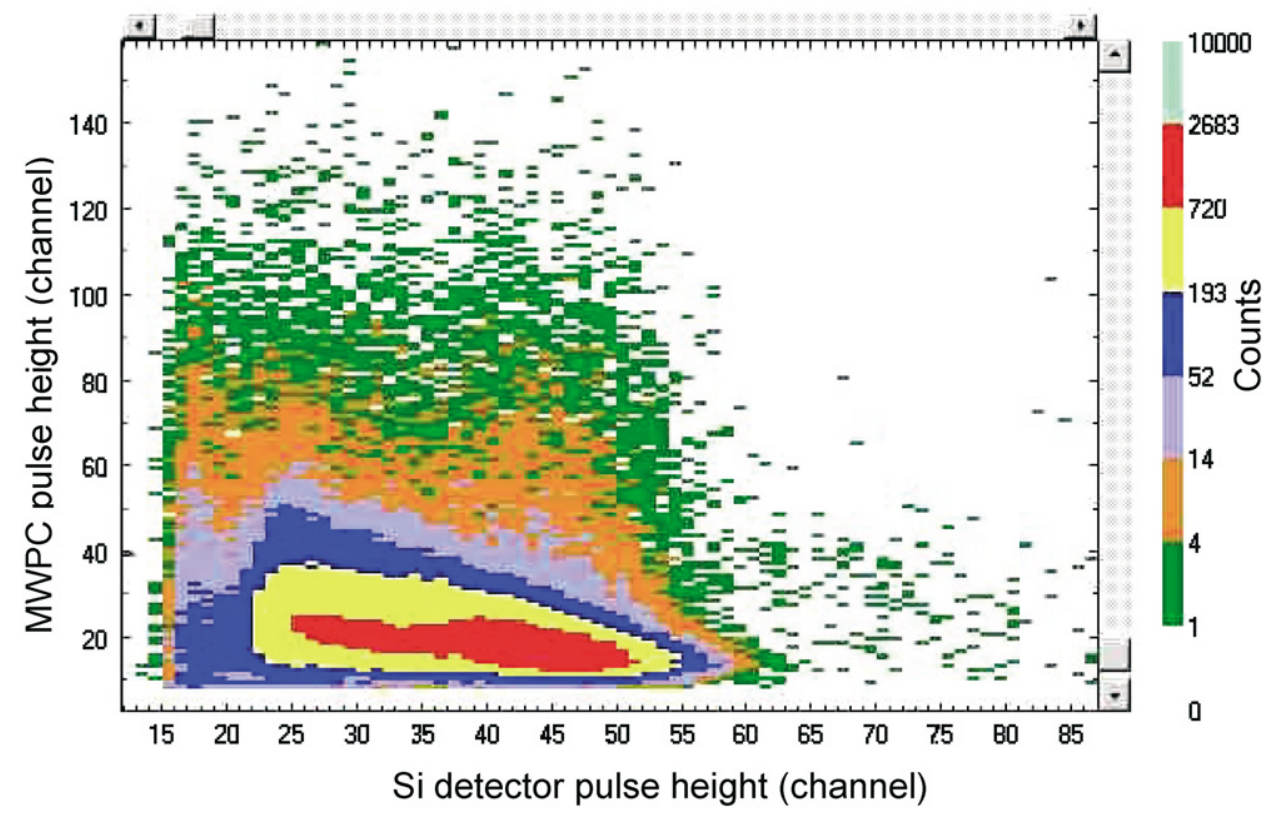

Fig. 6. Two-dimensional histogram of 63 and $85 \mathrm{keV} \mathrm{CE}$ coincident detection in the sample chamber for 1 atm xenon pressure and $900 \mathrm{~V}$ in the MWPC. 
With lower xenon pressure in the sample chamber the CEs will reach the silicon detector with higher energies. Higher gains will also allow efficient detection of lower energies in the MWPC. Fig. 6 depicts the coincidence two-dimensionalhistogram for both 63- and 85-keV CEs for 1-atm xenon in the MWPC. In this case, the GPSC detects any energy above $2 \mathrm{keV}$, detecting both the L-shell and the K-shell Ag X-rays.

The structure observed is the sum of the two lobes from 63- and 85-keV CEs. From channel 37 up to 58 in the silicon detector, the contribution of $85 \mathrm{keV}$ is dominant while for the channels below 37 the lower lobe indicates the presence of the 63$\mathrm{keV}$ CEs. The different X-ray energy for the two $\mathrm{CE}$ lobes distinguishes the events and creates separate histograms with the logic analyzer unit.

\section{Conclusions}

The compact, robust and low power consuming detection system described here has promising characteristics for radioxenon monitoring to verify compliance with test-ban treaties.

The detection system is capable of distinguishing the K-shell CEs with good energy resolution $(1.4 \mathrm{keV}$ at $30 \mathrm{keV}$ for X-rays and no greater than $25 \mathrm{keV}$ for electrons) in coincidence with the simultaneous characteristic X-rays. As the photon energy resolutions are considerably better than in other prototypes [5-7], background rejection is expected to be higher, allowing for lower minimum detectable activities.

The use of the gas detectors for photon counting also reduces the cosmic-ray background counting rate to about $1 \mathrm{~Bq}$, when compared with solid scintillators, further enhancing the anti-coincidence scheme for cosmic-ray rejection.
The detection of ${ }^{133} \mathrm{Xe}$ and ${ }^{135} \mathrm{Xe}$ decays also includes a beta particle in coincidence with the CEs. A coincidence scheme between the two silicon detectors and the MWPC is being considered, with the detection of the CE and beta in opposite $\mathrm{Si}$ detectors. The probability of such events is estimated to be $30 \%$ for the present sample chamber geometry. When detecting either a $214-\mathrm{keV} \mathrm{CE}$ from ${ }^{135} \mathrm{Xe}$ or a $45-\mathrm{keV} \mathrm{CE}$ from ${ }^{133} \mathrm{Xe}$, the determination of an energy above the region of interest (over $230 \mathrm{keV}$ ) will be identified clearly as a beta particle since cosmic-ray background is rejected in the GPSCs.

The efficiency of the system can still be improved by including the smaller contribution of the L-shell CEs. Although not considered at this point, the system can also include a surrounding layer of inorganic scintillators for gamma-ray detection to assure good detection efficiency for ${ }^{135} \mathrm{Xe}$ and ${ }^{133} \mathrm{Xe}$, which when added to ${ }^{133 \mathrm{~m}} \mathrm{Xe}$ and ${ }^{131 \mathrm{~m}} \mathrm{Xe}$ detection, will improve the sensitivity to the four xenon radioisotopes of interest.

\section{References}

[1] R.W. Perkins, L.A. Casey, Radioxenons: their role in monitoring a comprehensive test ban treaty, DOE/RL-9651 (PNNL-11201), Department of Energy, Washington DC, USA, June 1996.

[2] E. Browne, R. Firestone, Table of Radioactive Isotopes, Wiley, New York, 1986; National Nuclear Data Center, http://www.nndc.bnl.gov/nndescr.

[3] J.M.F. dos Santos, A.C.S.S.M. Bento, C.A.N. Conde, Nucl. Instr. and Meth. A 337 (1994) 427.

[4] G.F. Knoll, Radiation Detection and Measurements, 3rd Edition, Wiley, New York, 1999.

[5] G. Lamaze, Nucl. Instr. and Meth. A 385 (1997) 285.

[6] P.L. Reeder, T.W. Bowyer, Nucl. Instr. and Meth. A 408 (1998) 582.

[7] W.R. Russ, D.O. Stuenkel, B.D. Rooney, K.C. Gross, IEEE Trans. Nucl. Sci. NS46 (1999) 296. 